\title{
Bilateral corneal dermoids and eyelid malformation in a colt - a case report
}

\author{
Zita Makra ${ }^{1}$, Csaba Jakab² \\ University of Veterinary Science, ${ }^{1}$ Department and Clinic of Equine Medicine, Üllö, \\ ${ }^{2}$ Department of Pathology, Budapest, Hungary
}

Received July 9, 2017

Accepted April 3, 2018

\begin{abstract}
A 4-month-old colt was presented to the Department and Clinic of Equine Medicine, University of Veterinary Science, Hungary for the evaluation of chronic bilateral mucopurulent discharge and mild blepharospasm. On ophthalmic examination, pigmented skin with long hairs located ventrotemporally on both corneas, a cluster of aberrant long hairs protruding from both caruncles and medial canthi, and a duplicated inferior eyelid of the left eye were identified. Surgical excision of limbic dermoids on both eyes and blepharoplasty appeared curative at the 6-month post-operative follow-up. This case report describes unusually located bilateral limbic dermoids in a horse. In addition, the dermoid on the left eye was accompanied by eyelid malformation. This unique combination of ocular congenital lesions has not been described in a horse so far.
\end{abstract}

Blepharoplasty, cornea, horse, superficial keratectomy

Choristomas are congenital lesions representing normal tissue in an abnormal location. Ocular examples of choristomas are epibulbar dermoid, ectopic lacrimal gland or episcleral osseous choristoma (Mansour et al. 1989). Ocular dermoids are non-progressive, unilateral or bilateral lesions consisting of epithelial and dermis-like components on the cornea, limbus, conjunctiva or the third eyelid (Cook 2007; Clode and Matthews 2011). They are found in all species and known to be inherited in Hereford cattle and occasionally familial in humans (Barkyoumb and Leipold 1984; Mansour et al. 1989; Maggs 2008). Ocular dermoids in horses have been reported in a group of related Quarter Horses in association with iridal hypoplasia and cataracts, in a Standardbred colt with no other ocular abnormality, and as a third eyelid dermoid in a Gypsy Vanner gelding causing chronic recurrent corneal ulcers (McLaughlin 1983; Joyce et al. 1990; Greenberg et al. 2012). To the authors' knowledge, this is the first case report describing bilateral dermoids combined with an eyelid malformation in a horse.

\section{Case report}

A 4-month-old Hungarian sport horse colt was presented to the Department and Clinic of Equine Medicine, University of Veterinary Science, Üllö for the evaluation of abundant chronic bilateral mucopurulent discharge and mild blepharospasm. The colt was in good body condition and had no other clinical signs of illness, the clinical indicators were within normal range.

\section{Initial ophthalmic examination}

Ophthalmic examination revealed mild blepharospasm, slightly injected conjunctiva and a remarkable mucopurulent discharge from both eyes. Direct and consensual pupillary light reflex (PLR), dazzle, corneal and palpebral reflex, and menace response were positive in both eyes (OU). Dermoids, located ventro-temporally on both corneas (approximately 
$15 \times 10 \mathrm{~mm}$ in size), appeared to be pigmented, as a bulged-out tissue from the corneal surface and had approximately $2-3 \mathrm{~cm}$ long hairs. A cluster of aberrant $1-2 \mathrm{~cm}$ long hairs protruding from both caruncles and medial canthi OU and duplicated inferior eyelid (double eyelid margins and conjunctival fornices) of the left eye (OS) were identified. The dermoids occupied one third of the corneas, and in the left eye covered the cornea, limbus and bulbar conjunctiva from approximately 2 to 7 o'clock, in the right eye from 5 to 10 o'clock. The corneal dermoids were pigmented and had rugged, slightly nodular surface, the corneal margin of the dermoids was heavily pigmented, and the adjacent cornea was oedematic. The area where hair touched the cornea was oedematic, too. Fluorescein dye revealed no stain uptake. Intraocular pressure (IOP) was $20 \mathrm{mmHg}$ of the right eye (OD) and $24 \mathrm{mmHg}$ of the left eye (OS) (TonoVet, Finland). Biomicroscopic examinations of the remaining anterior segments were within normal limits (SL-14 Portable Slit Lamp, Kowa, Japan). The posterior segments were normal in both eyes examined with an indirect ophthalmoscope (Heine Omega 500 indirect ophthalmoscope, +20D aspheric lens, Heine, Germany). The hairs, growing from the hair follicles of the dermoid, caused conjunctival and corneal irritation which resulted in conjunctivitis, mucopurulent discharge and keratitis (Plate V, Fig. 1).

\section{Surgical management}

For the treatment of ocular dermoids the surgery is generally performed to improve vision or cosmetic appearance, to impede growth and to abolish conjunctival and corneal irritation and subsequent inflammation. Dermoids are treated by careful surgical excision by conjunctivectomy and superficial keratectomy (Slatter 2001). In this case general anaesthesia was introduced after sedation (4 mg acepromazine - Calmivet $5 \mathrm{mg} / \mathrm{ml}$ Vetoquinol, Lure cedex, France; $220 \mathrm{mg}$ xylazine- CP-Xylazin 2\% Medicus Partner Kft. Biatorbágy, Hungary; $7 \mathrm{mg}$ butorphanol- Morphasol $10 \mathrm{mg} / \mathrm{ml}$ Medicus Partner Kft. Biatorbágy, Hungary), and induction (300 mg ketamine- Ketanest $100 \mathrm{mg} /$ $\mathrm{ml}$ bela-pharm $\mathrm{GmbH}$, Vechta, Germany; $5 \mathrm{mg}$ diazepam - Seduxen $5 \mathrm{mg} / \mathrm{ml}$ Richter Gedeon Nyrt, Budapest, Hungary), then maintained with isoflurane (ET 1-3\%, Isofluran CP $1 \mathrm{ml} / \mathrm{ml} \mathrm{Medicus} \mathrm{Partner} \mathrm{Kft.} \mathrm{Biatorbágy,} \mathrm{Hungary)} \mathrm{and} \mathrm{medetomidine} \mathrm{CRI}$ $(0.0035 \mathrm{mg} / \mathrm{kg} / \mathrm{h}$ - Cepetor $1 \mathrm{mg} / \mathrm{ml}$ Medicus Partner Kft. Biatorbágy, Hungary). Topical anaesthesia $(0.4 \%$ oxibuprocaine eyedrop - Novesine $0.4 \%$ Augentropfen OmniVision $\mathrm{GmbH}$, Puchheim, Germany) was used to anaesthetize the cornea and conjunctiva in both eyes. The foal was first positioned in left, and then in right lateral recumbency. Superficial keratectomy with a mini flat lamellar Beaver blade with a rounded tip (Eickemeyer, Germany) and conjunctivectomy with a Beaver blade and Westcott scissors (Eickemeyer, Germany) were carried out after lateral canthotomy (Plate V, Fig. 2). The keratectomy site was left uncovered; the scleral conjunctivectomy site was repaired with transposition of the fornical conjunctiva and sutured to the sclera at the limbus with continuous suture pattern using polyglactin 910 USP 4-0 suture material (Vicryl Ethicon, Johnson \& Johnson International) (Plate VI, Fig. 3). The excised specimens were submitted for histopathology. Hairy skin was excised from the medial canthus of both eyes. For the treatment of the doubled inferior eyelid of the left eye, a blepharoplasty was performed with the excision of the inner (doubled) eyelid margin and the palpebral conjunctiva was sutured as previously described.

\section{Histopathologic examination}

Histopathology of the excised tissue revealed orthokeratotic hyperkeratosis, mild hyperplastic stratified squamous epithelium, moderate lymphocytic dermal infiltration, multiple disorganized intact hair follicles, several of them with accompanying sebaceous glands, additional apocrine glands in the dermis rich in collagen bundles (Plate VI, Fig. 4). 
Limbal dermoid usually shows a keratinized stratified squamous epithelium covering the surface of the lesion with hair shafts and adnexal structures in the substantia propria (Grahn and Peiffer 2007). Here sebaceous glands were prominently displayed. In addition, the loose collagen of the substantia propria was replaced with dense collagen in thick bundles and moderate chronic inflammatory infiltrate was also noted. The hairs and their follicles were completely excised.

Histologically, the presence of hair with sebaceous glands and overlying squamous epithelium was consistent with the dermoid of the cornea and bulbar conjunctiva in both eyes.

\section{Outcome/Follow-up}

Postoperative treatment was carried out with subpalpebral lavage tubes (SPL, Equivet ocular kit Fr 5, Kruuse, Denmark) placed in the dorsal conjunctival fornix of both eyes. Topical medication consisting of chloramphenicol $10 \mathrm{mg} / \mathrm{ml}$ compounded eye drop, $1 \%$ atropine compounded eye drop, autologous serum and $0.2 \%$ sodium hyaluronate eye drop (Hyaline, LCA Pharmaceutical) was applied via SPL four times per day (QID). Additionally, $1.1 \mathrm{mg} / \mathrm{kg}$ flunixin meglumine (Flunidol MLS $50 \mathrm{mg} / \mathrm{ml}$ Medicus Partner Kft. Biatorbágy, Hungary) was administered intravenously once a day (SID) for 4 days. The keratectomy site was considered to be healed by 14 days post-operatively, when neither cornea retained the fluorescein dye. Then topical medications were tapered and discontinued. At a 6-month follow-up, the colt had comfortable eyes with small corneal scars remaining close to the limbus and a good eyelid function (Plate VII, Fig. 5).

\section{Discussion}

Dermoids are rare in horses, they clinically resemble skin and are usually noticed shortly after birth. Only three cases have been described in the horse, in particular: a case of bilateral ocular dermoids in a yearling Standardbred colt (McLaughlin 1983), limbal dermoids with aniridia in quarter horses (Joyce et al. 1990), and a third eyelid dermoid (Greenberg et al. 2012). Bilateral dermoids in the ventro-temporal cornea with palpebral malformation have not been described so far. In our case the dermoids were seen occupying the ventro-temporal cornea, in contrast to the cases in the references where they were dorso-temporal (McLaughlin 1983; Joyce et al. 1990). The foal's dam, sire and known siblings were free of any ocular abnormalities, so we suspect that these congenital lesions can be the result of a gene mutation. Limbic dermoids can be combined with other ocular dysplasia (Latimer and Wyman 1983), in our case with eyelid malformation. In a similar case bilateral iridial hypoplasia with congenital cataracts were described in a Quarter horse stallion and a group of his offspring as a result of an independent mutation. These defects were suspected to be transmitted to his offspring by an autosomal dominant gene (Joyce et al. 1990).

In our case the long hairs growing from the dermoids touched the cornea, resulting in focal oedema in the affected region, however, without scrubbing the corneal epithelium or causing ulceration. The short stinging hair caused chronic, recurrent corneal ulcers in the case of a third eyelid dermoid (Greenberg et al. 2012).

Some deep corneal dermoids cannot be removed without leaving a scar, although superficial keratectomy is successful in many cases (Slatter 2001). The superficial stroma was removed with keratectomy in this case and the residual scarring was not in the visual axis and therefore did not interfere with vision. Interestingly, the periphery of the keratectomy sites underwent conjunctivalization, so ultimately the ventro-temporal limbus was covered with conjunctiva. Equine corneal epithelial stem cells (CESCs) were isolated at the corneal limbus and had the same immunostaining pattern as human 
CESCs (Moriyama et al. 2014). These equine CESCs were localized in the epithelial basal layer of the corneal limbus, where melanocytes reside. The limbal palisades of Vogt and the interpalisade rete ridges are thought to be repositories of stem cells. The limbal microenvironment is considered to have an important role in maintaining the stemness of stem cells. Limbal stem cells act as a "barrier" to conjunctival epithelial cells, furthermore preventing their migration onto the corneal surface. Under certain conditions, such as a surgical procedure at the location of the limbus, resident stem cells may be depleted to a certain degree, resulting in varying degrees of stem cell deficiency which can appear later as abnormally changed corneal surface. Such deficiency of limbal stem cells leads to "conjunctivalization" of the cornea with vascularization, presence of goblet cells, and an irregular epithelium (Dua and Azuara 2000). We suspect that the sensitive limbal stem cells were damaged during keratectomy and therefore conjunctival epithelial cells could cover the limbus at the previous keratectomy site. The excision of the duplicated inferior eyelid and the limbal dermoids appeared curative at the 6-month post-operative follow-up.

\section{References}

Barkyoumb SD, Leipold HW 1984: Nature and cause of bilateral ocular dermoids in hereford cattle. Vet Pathol 21: $316-324$

Clode AB, Matthews AG 2011: Diseases and surgery of the cornea. In: Gilger BC (Ed.): Equine Ophthalmology. Elsevier Saunders, Maryland Heights, pp 181-266

Cook CE 2007: Ocular embryology and congenital malformations. In: Gelatt KN (Ed.): Veterinary Ophthalmology. Blackwell Publishing, Ames, pp 3-36

Dua HS, Azuara-Blanco A 2000: Limbal stem cells of the corneal epithelium. Surv Ophthalmol 44: 415-425

Grahn B, Peiffer R 2007: Fundamentals of veterinary ophthalmic pathology. In: Gelatt KN (Ed.): Veterinary Ophthalmology. Blackwell Publishing, St Louis, pp 355-437

Greenberg SM, Plummer CE, Brooks DE, Craft SL, Conway JA 2012: Third eyelid dermoid in a horse. Vet Ophthalmol 15: 351-354

Joyce JR, Martin JE, Storts RW, Skow L 1990: Iridal hypoplasia (aniridia) accompanied by limbic dermoids in a group of related quarterhorses. Equine Vet J Suppl 2: 26-28

Latimer CA, Wyman M 1985: Neonatal ophthalmology. Vet Clin N Am-Equine 1: 235-259

Maggs DJ 2008: Conjunctiva. In: Maggs DJ (Ed.): Slatter's Fundamentals of Veterinary Ophthalmology. Saunders Elsevier, St. Louis, pp 135-150

Mansour AM, Barber JC, Reinecke RD, Wang FM 1989: Ocular choristomas. Surv Ophthalmol 33: 339-358

McLaughlin SA, Brightman AH 1983: Bilateral ocular dermoids in a colt. Equine Pract 5: 10-14

Moriyama H, Kasashima Y, Kuwano A, Wada S 2014: Anatomical location and culture of equine corneal epithelial stem cells. Vet Ophthalmol 17: 106-112

Slatter D 2001: Fundamentals of Veterinary Ophthalmology. Saunders, Philadelphia, 208 p. 
Plate V

Makra Z. et al.: Bilateral corneal ... pp. 73-76

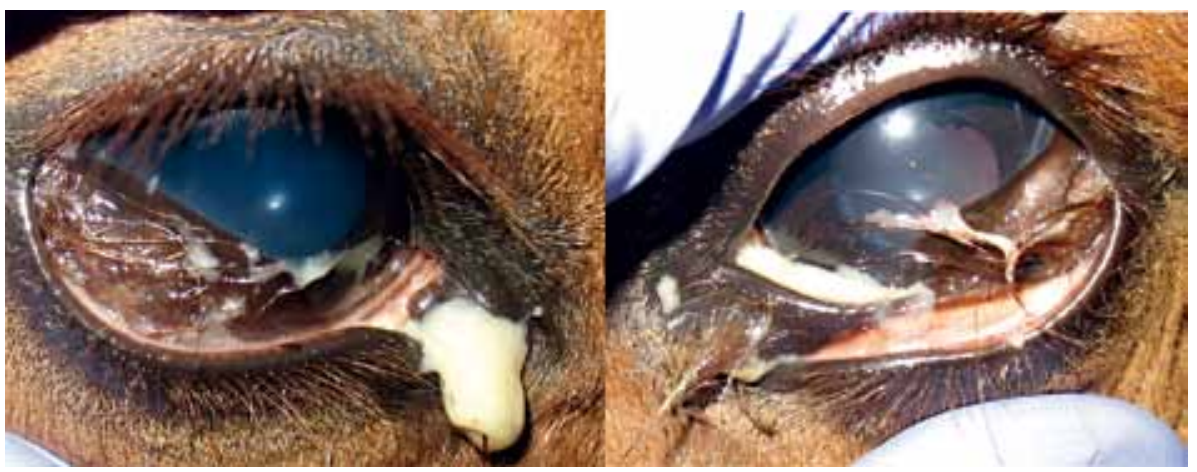

Fig. 1. The right and left eyes at the time of presentation. The dermoids covered one-third of the ventrotemporal cornea, the inferior eyelid of the left eye was duplicated. Note the abundant mucopurulent discharge.

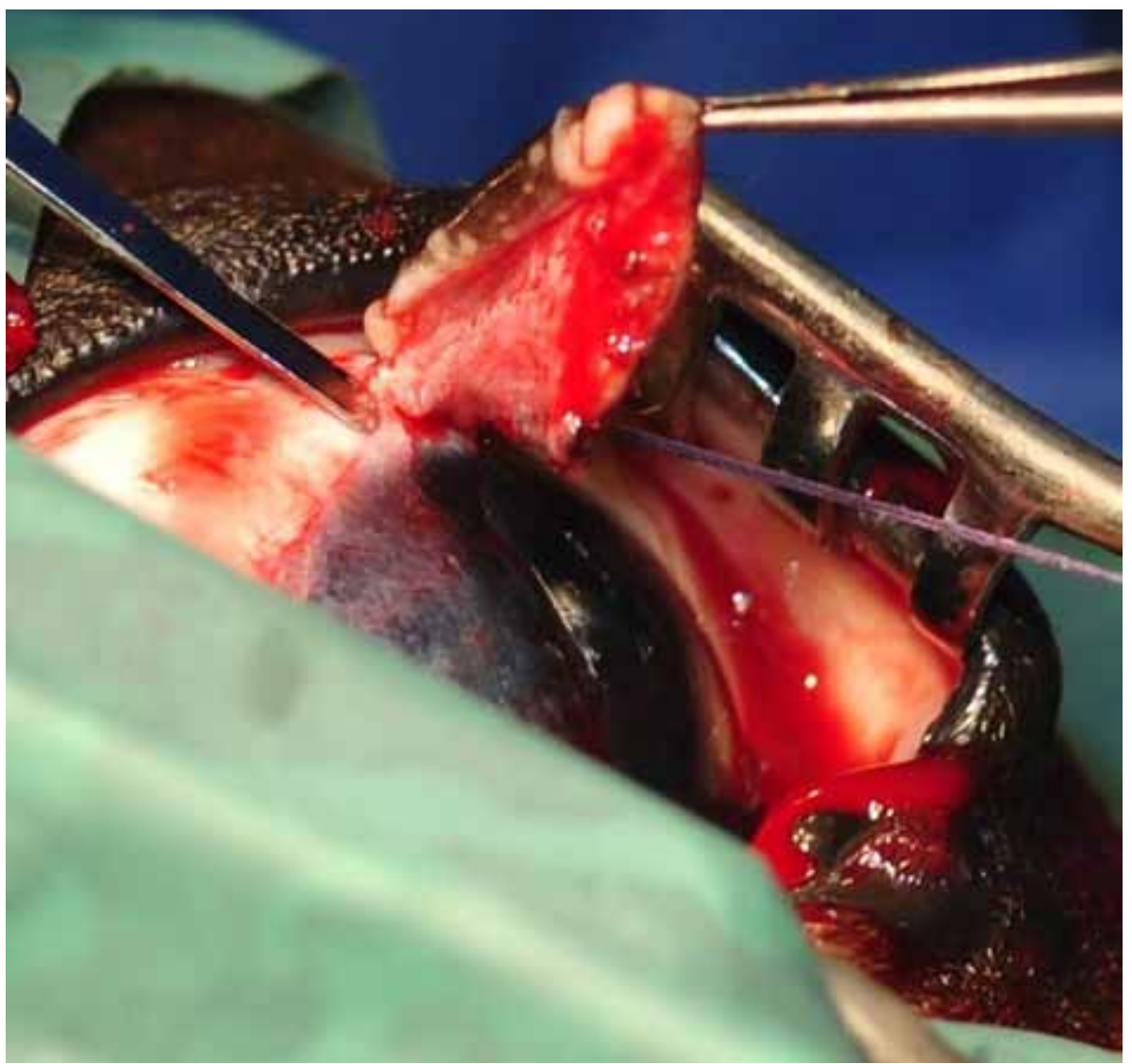

Fig. 2. Intraoperative image of the right eye (OD), excision of the dermoid. 


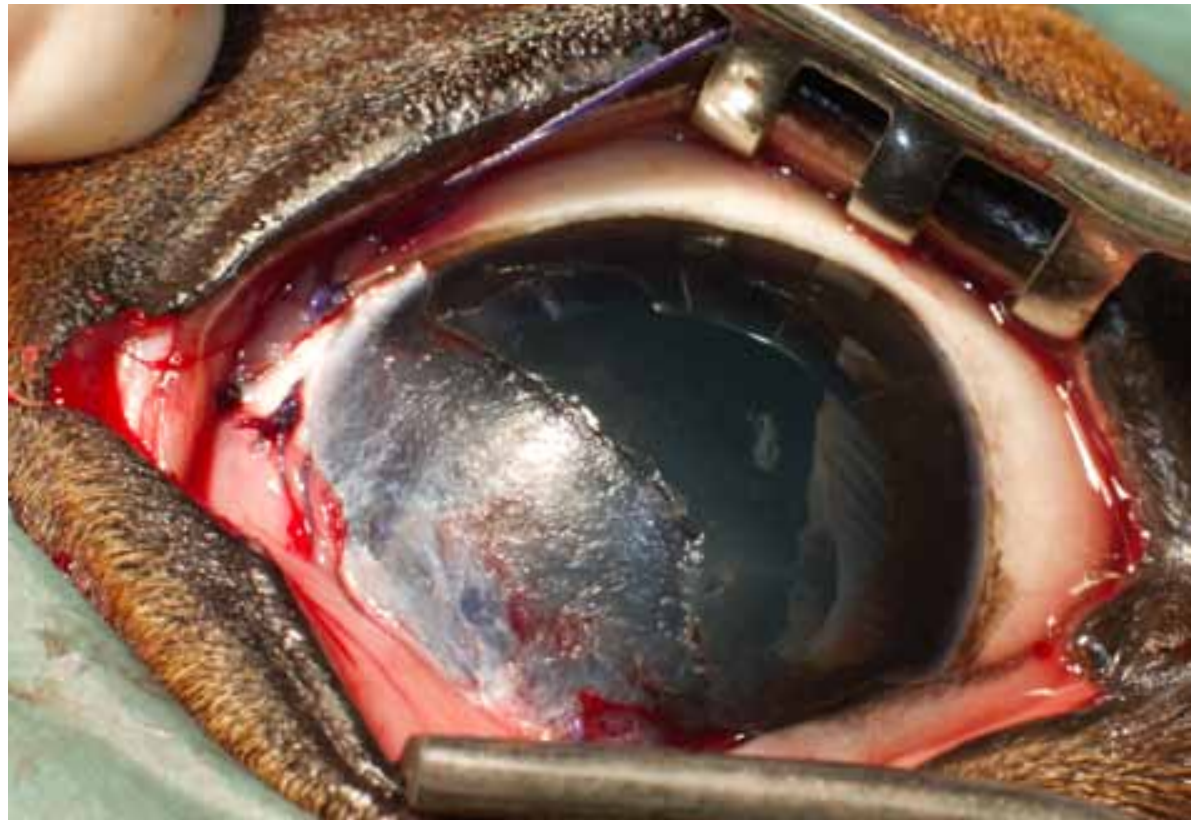

Fig. 3. Right eye, immediately post-dermoid excision.

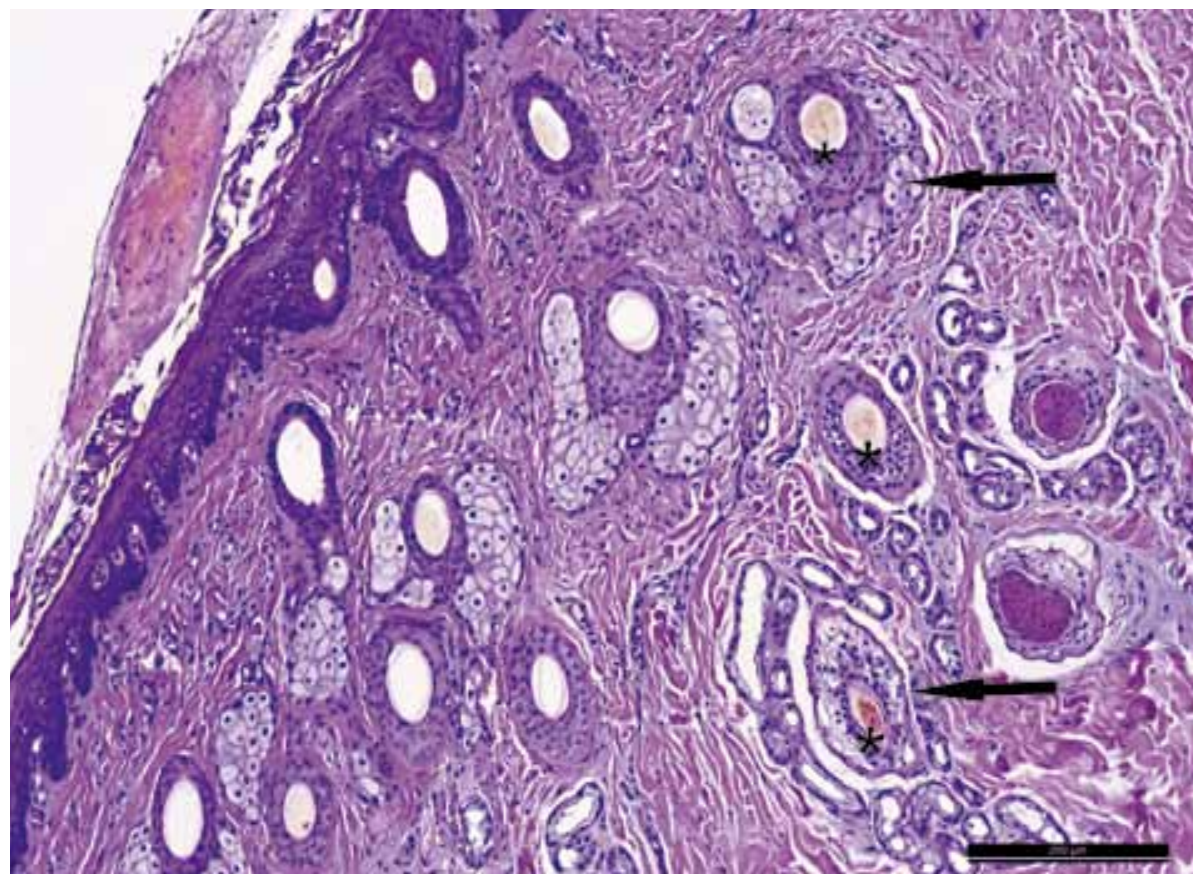

Fig. 4. Histological image of a section of the excised dermoid. Hair follicles (asterisks), glandular elements (arrows) and inflammatory infiltrate were seen. Three marked single hair follicles were associated with sebaceous glands in the image (Haematoxylin and eosin, $\times 100$ ). 


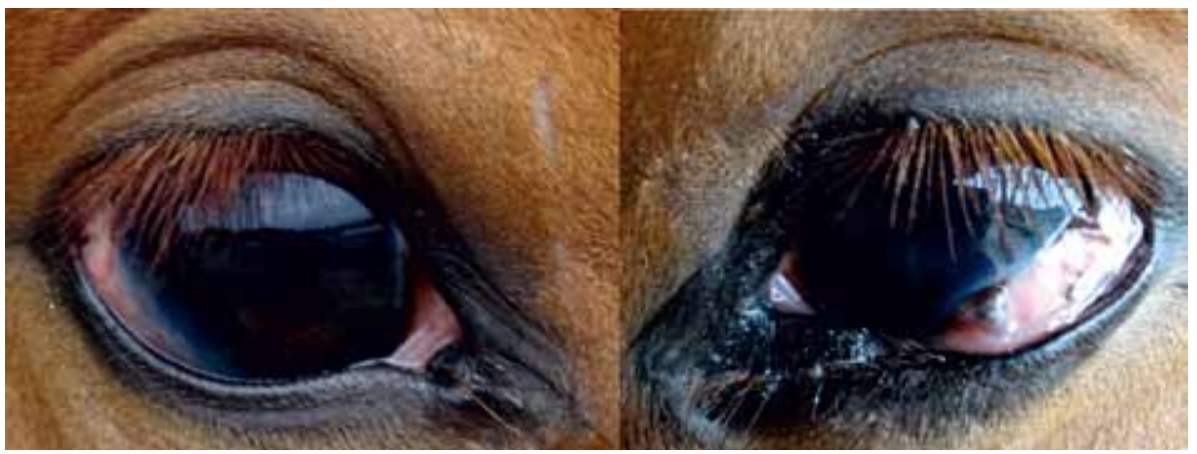

Fig. 5. The right and left eyes are shown as they appeared 6 months after surgical excision of the dermoids and eyelid correction. The eyes are comfortable, note the conjunctivalization of the cornea at the periphery of the previous ketarectomy site. 